\title{
Range Operation Studies of Microbial Fermentation for Biopharmaceutical Applications
}

\author{
Lalintip Hocharoen ${ }^{1 *}$, Kosin Jittipanyakul ${ }^{2}$ \\ ThianThale 25, Thakam, Bangkhunthian, BKK Thailand 10150. \\ Thakam, Bangkhunthian, BKK Thailand 10150. \\ * Corresponding author. Tel.: (66)2-470-7439; email: lalintip.hoc@kmutt.ac.th \\ Manuscript submitted December 14, 2015; accepted April 6, 2016. \\ doi: 10.17706/ijbbb.2016.6.2.26-33
}

1 National Biopharmaceutical Facility (NBF), King Mongkut's University of Technology Thonburi 49

${ }^{2}$ Chemical Engineering Department, King Mongkut's University of Technology Thonburi 49 ThianThale 25,

\begin{abstract}
The production of biopharmaceutical in lab scale differs from in pilot plant-scale particularly in process control or conditions control aspects. For larger volume of production, there is a chance of having deviation on controlling the operating conditions that is likely to have effects on specifications of biopharmaceuticals. Thus, this work focused on the optimization and robustness study of growth conditions on microbial fermentation using design of experiment methodology (DoE) and statistical analysis approach. Three factors for designing experiment were temperature, $\mathrm{pH}$ and \% dissolved oxygen (D0). A high-throughput MRT-24 microbioreactor and Pichia pastoris KM71H which expresses Japanese Encephalitis virus envelope protein were used as a model study and the measured output was $\mathrm{OD}_{600}$. After 17 hours of fermentation, the data was analyzed and the conditions where temperature was $28.0^{\circ} \mathrm{C}$, $\mathrm{pH}$ was 6.37 and DO was $30 \%$ were calculated to be the optimized value. Then the robustness study was carried out in which $5 \%$ loss of the highest yield was set as a criterion. The results predicted that the robust range was temperature of $28^{\circ} \mathrm{C}$ to $29.5^{\circ} \mathrm{C}$ and $\mathrm{pH}$ of 6.0 to 6.5 .
\end{abstract}

Key words: Design of experiment, microbioreactor, Pichiapastoris, robustness, ranges of operations.

\section{Introduction}

Biopharmaceuticals production has become significantly of interest among global healthcare-product market in the world where the sale market reaches 116 million US dollars in 2009 and it is expected to have $11.2 \%$ increase by 2016 [1], [2]. In Thailand, biopharmaceuticals production is still in the early beginning phase where researchers are developing the best candidates for cure which is in a lab-scale study [3]. However, the lab-scale production of biopharmaceutical differs from that of in pilot-scale particularly in process control or conditions control aspects. With the larger volume of production, there is a chance of having deviation on controlling the operating conditions that is likely to have effects to the specifications of biopharmaceuticals and consequently the qualities of the product maybe questioned. For example, the temperature of pilot-scale bioreactor is hard to control because the distribution of heat in larger volume is lower than the distribution of heat in lab-scale [4], [5]. Thus, the temperature of pilot-scale bioreactor is not stable at all-time [5]. Moreover, there is a few literatures reviewing on range of operating conditions and lab-scale research mainly focuses on optimal conditions while biopharmaceutical industry requires the information to support the operating conditions to assure the products remain good qualities. Therefore, 
the industry has to focus on their range of operating conditions and find significant parameters to control the process.

Herein we demonstrated the ranges of operations of growing Pichia pastoris using a strainKM71H which contains plasmids encoding Japanese Encephalitis Virus envelope protein as a case study. Pichia pastoris is one of the most common strains used in biopharmaceutical productions due to a number of advantages including its high growth rate coupled with ease of high cell-density fermentation, a simple and cheap growth medium to use and high levels of protein productivities and post translational modification applications [6]-[12].

The study was performed by using MRT-24 microbioreactors where parallel growth conditions can be high-throughput analyzed. The ranges were studied for factors including temperature, $\mathrm{pH}$ and \%Dissolved Oxygen (\%DO).

\section{Materials and Methods}

\subsection{Cell Stocks Preparation}

Pichia pastoris KM71H containing Japanese Encephalitis Virus (JEV) envelope protein gene was obtained as a gift from Assist. Prof. Anan Tongta and Dr. Jorgen Borg at KMUTT. The glycerol stocks were prepared in YPD and $50 \%$ glycerol then stored at $-80^{\circ} \mathrm{C}$ for further use.

\subsection{Media, Buffer, and Chemicals Preparation}

YPD and BMGY were prepared as described in [4]. 10\% Pluronic-68 used as antifoam reagent was prepared by diluting with deionized water then sterilized by an autoclave at $121^{\circ} \mathrm{C}$ for 20 minutes. $15 \%$ $\mathrm{NH}_{4} \mathrm{OH}$ was also prepared by dilution manner then was poured into a pressurized vessel for ammonia vapor production used in $\mathrm{pH}$ adjustment during fermentation in MRT-24 microbioreactor.

\subsection{Design of Experiment (DoE) and Statistical Analysis}

Minitab program was used to conduct a Box-Behnken Design (BBD) model for three factors which are temperature $\left(\mathrm{T},{ }^{\circ} \mathrm{C}\right), \mathrm{pH}$ and \%Dissolved Oxygen (\%DO). Levels of BBD design was chosen based on the growth characteristics of Pichia pastoris and JEV envelope protein properties. Table 1 displays high, medium and low levels for each factor that were used to create the 15 BBD experimental runs shown in Table 2.

Table 1. Factors and Their Levels

\begin{tabular}{|c|c|c|c|}
\hline \multirow{2}{*}{ Factors } & \multicolumn{3}{|c|}{ Level } \\
\cline { 2 - 4 } & Low & Medium & High \\
\hline $\mathrm{T}\left({ }^{\circ} \mathrm{C}\right)$ & 28 & 30 & 32 \\
\hline $\mathrm{pH}$ & 5.5 & 6.0 & 6.5 \\
\hline$\% \mathrm{DO}$ & 10 & 20 & 30 \\
\hline
\end{tabular}

The predictive model from the results of experiments was achieved by using Minitab program and shown in equation 1 where some terms were removed regarding the p-values. The summary of fit, ANOVA and response surface analysis were also demonstrated in table below.

\subsection{Yeast Culturing Conditions and Microbioreactor Set up}

Overnight cultivation of Pichia pastoris $\mathrm{KM} 71 \mathrm{H}$ was conducted in a shake flask manner at $30^{\circ} \mathrm{C}$ and 300 $\mathrm{rpm}$. Cells were harvested when the $\mathrm{OD}_{600}$ reaches 8 to 10 by centrifugation at $5000 \mathrm{rpm}$. The pellets were then resuspended in BMGY with its corresponding $\mathrm{pH}$ conditions to the $\mathrm{OD}_{600}$ of 1 . The resuspension was transferred to MRT-24 plates to their corresponding assigned positions where a mixture of anti-foam and BMGY were pre-loaded. $\mathrm{pH}$ and DO optical sensors, in the bottom of the plate, were calibrated before the 
cell resuspension was transferred to the plate. PALL MRT-24 microbioreactor was employed for culturing MRT-24 plates overnight at designed experimental runs listed in Table 2. The growth of Pichia pastoris KM71Hexpressing JEV envelope protein was then checked by an off-line $\mathrm{OD}_{600}$ measurement. The Mrt-24 microbioreactor was set to agitate at $500 \mathrm{rpm}$ and gases flows were $10 \mathrm{sccm}$ for $\mathrm{CO}_{2}$ and $\mathrm{NH}_{4} \mathrm{OH}$ and 20 $\mathrm{sccm}$ for $\mathrm{O}_{2}$.

\section{Results and Discussion}

BBD was chosen for this study as comparing to other models as BBD creates a reduced experimental run numbers that are sufficient to cover factors to be investigated [13]-[16]. 15 experimental runs had been created and the responses were $\mathrm{OD}_{600}$ measurements shown in Table 2 below. The responses were varied from 13.4 to 35.6 among which there were three runs marked with double asterisks where the DO sensor did not show any responses while the oxygen had been feeding in. The center point experiments were also indicated with an asterisk in Table 2.

Table 2. Experimental Runs and Their Responses

\begin{tabular}{|c|c|c|c|c|c|c|}
\hline $\begin{array}{c}\text { Randomized } \\
\text { run no. }\end{array}$ & $\mathrm{T}\left({ }^{\circ} \mathrm{C}\right)$ & $\mathrm{pH}$ & $\% \mathrm{WO}$ & \multicolumn{3}{|c|}{ OD $_{\text {600 }}$} \\
\hline 4 & 28 & 6 & 30 & 32.4 & 31.88 & 32.7 \\
\hline 6 & 28 & 6 & 10 & 31.55 & 29.2 & 31.45 \\
\hline 9 & 28 & 6.5 & 20 & $19.1^{* *}$ & 24.45 & 21.8 \\
\hline 15 & 28 & 5.5 & 20 & 19.5 & 23.2 & 20.55 \\
\hline $3^{*}$ & 28 & 6 & 20 & 29.55 & 27.19 & 22.75 \\
\hline 5 & 30 & 5.5 & 10 & 24.05 & 23.1 & 29.25 \\
\hline $7^{*}$ & 30 & 6 & 20 & 29.55 & 27.19 & 22.75 \\
\hline 8 & 30 & 5.5 & 30 & 23.55 & 23.55 & 17.95 \\
\hline 10 & 30 & 6.5 & 10 & 19.9 & 20.85 & 19.7 \\
\hline 12 & 30 & 6.5 & 30 & 22.2 & 35.6 & 34.25 \\
\hline $14^{*}$ & 30 & 6 & 20 & 29.55 & 27.19 & 22.75 \\
\hline 1 & 32 & 6.5 & 20 & 20.75 & 21.2 & 20.65 \\
\hline 2 & 32 & 6 & 30 & $22.9 * *$ & 20.35 & 20.2 \\
\hline 11 & 32 & 6 & 10 & 17.5 & 20.75 & 21 \\
\hline 13 & 32 & 5.5 & 20 & $20.1^{* *}$ & 19.9 & 13.4 \\
\hline
\end{tabular}

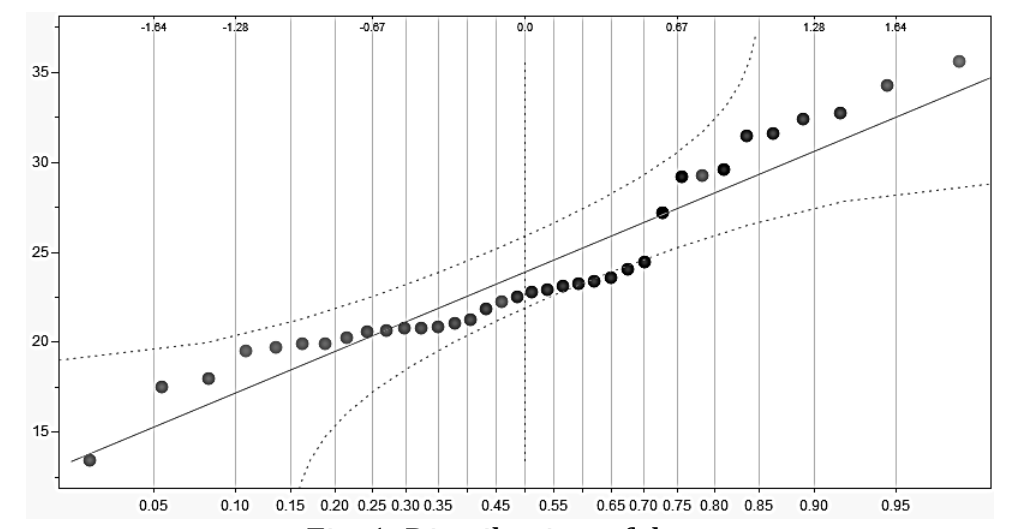

Fig. 1. Distribution of data.

Moreover, the distribution plot was generated as illustrated in Fig. 1. From the graph, one observation 
was the experiments ran at \%DO of 30 seemed to show higher responses than others. This might be that Pichia pastoris generally requires a lot of oxygen for growing. The more oxygen fed in, the more cells grow. In overall, the data distribution was proper for further statistical analysis.

Statistical analysis was performed and listed in Table 3. The $R^{2}$ of 0.67 as well as $R^{2}$ adj of 0.59 were obtained suggesting that the predicted model was in range of acceptable as several literatures reported the value $>0.75$ being considered as good model and $<0.25$ being poor [16]-[18]. Moreover, $p$-value from Table 4 and lack of fit value from Table 5 also indicated that the predicted model was suitable for pursuing further response surface analysis.

Table 3. Summary of Fit

\begin{tabular}{|l|l|}
\hline $\mathbf{R}^{\mathbf{2}}$ & 0.668528 \\
\hline $\mathbf{R}^{\mathbf{2}}$ adj & 0.585659 \\
\hline Root Mean Square Error & 3.367795 \\
\hline Mean of Response & 23.91083 \\
\hline Observations & 36 \\
\hline
\end{tabular}

Table 4. The Analysis of Variance

\begin{tabular}{l|ccccc}
\hline Source & DF & Sum of Squares & Mean Square & F Ratio & Prob>F \\
\hline Model & 7 & 640.50276 & 91.5004 & 8.0674 & $<0.0001$ \\
Error & 28 & 317.57712 & 11.3420 & - & - \\
C. Total & 35 & 958.07988 & - & - & - \\
\hline
\end{tabular}

Table 5. Lack of Fit Analysis

\begin{tabular}{l|cccccc}
\hline Source & DF & Sum of Squares & Mean Square & F Ratio & Prob>F & Max R Sq \\
\hline Lack Of Fit & 5 & 83.10479 & 16.6210 & 1.6304 & 0.1919 & 0.7553 \\
Pure Error & 23 & 234.47233 & 10.1944 & - & - & - \\
Total Error & 28 & 317.57712 & - & - & - & - \\
\hline
\end{tabular}

Table 6. Response Surface Statistical Analysis

\begin{tabular}{c|cccc}
\hline \multicolumn{5}{c}{ Parameter Estimates } \\
\hline Term & Estimate & Std Error & t Ratio & Prob>ItI \\
\hline Intercept & 25.4975 & 1.683897 & 15.14 & $<.0001$ \\
$\mathrm{~T}(28,32)$ & -3.566972 & 0.756508 & -4.72 & $<.0001$ \\
$\mathrm{pH}(5.5,6.5)$ & 1.394724 & 0.721302 & 1.93 & 0.0633 \\
$\mathrm{DO}(10,30)$ & 1.330092 & 0.724634 & 1.84 & 0.0771 \\
$\mathrm{~T}^{*} \mathrm{~T}$ & -1.602824 & 1.231878 & -1.30 & 0.2038 \\
$\mathrm{pH} \mathrm{pH}$ & -3.354676 & 1.231878 & -2.72 & 0.0110 \\
$\mathrm{pH}$ D0 & 3.595833 & 0.972199 & 3.70 & 0.0009 \\
$\mathrm{DO}$ * DO & 2.336342 & 1.231878 & 1.90 & 0.0682 \\
\hline
\end{tabular}

Table 6 provides the regression coefficients and the associated probability values ( $p$-value) for $\mathrm{OD}_{600}$ response. The linear terms of temperature and intercept were statistically significant parameters affecting the $\mathrm{OD}_{600}$, since their $p$-values were $<0.05$. Only the quadratic term of $\mathrm{pH}$ was significant meaning that $\mathrm{pH}$ was probable affecting the response. The only interaction term between $\mathrm{pH}$ and DO was also statistically significant with a $p$-value of 0.0009 . These results indicate that the three parameters are important parameters for the growth of Pichia pastoris KM71H. Consequently, the predicted equation was generated 
as in equation (1).

$$
\begin{gathered}
O D_{600}=25.45-3.16\left[\frac{(T-30)}{2}\right]+1.12\left[\frac{(p H+6)}{0.5}\right]+1.20\left[\frac{(D O-20)}{10}\right]-2\left[\frac{(T-30)}{2}\right]^{2}-3.48\left[\frac{(p H+6)}{0.5}\right]^{2}+ \\
2.46\left[\frac{(D O-20)}{10}\right]^{2}+3.6\left[\frac{(p H+6)}{0.5}\right]\left[\frac{(D O-20)}{10}\right]
\end{gathered}
$$

The response surface plots were shown in Fig. 2 in which Fig. 2A illustrates the relationship of temperature and $\mathrm{pH}$ where the optimal growth conditions were achieved at the highest point of the curve. While the plots of \%DO either with pH in Fig. 2B or temperature in Fig. 2C demonstrates that higher \%DO renders better yields which is consistent with other research groups. However, due to limitation of the high-throughput equipment, the control of higher \%DO (>30\%) is quite difficult. For temperature plots, it was obviously seen that the lower temperature is preferred. Based on these predicted model, the highest response was calculated to be an $\mathrm{OD}_{600}$ around 32 and the prediction interval was 29.4 to 36.6 as listed in Fig. 2D.
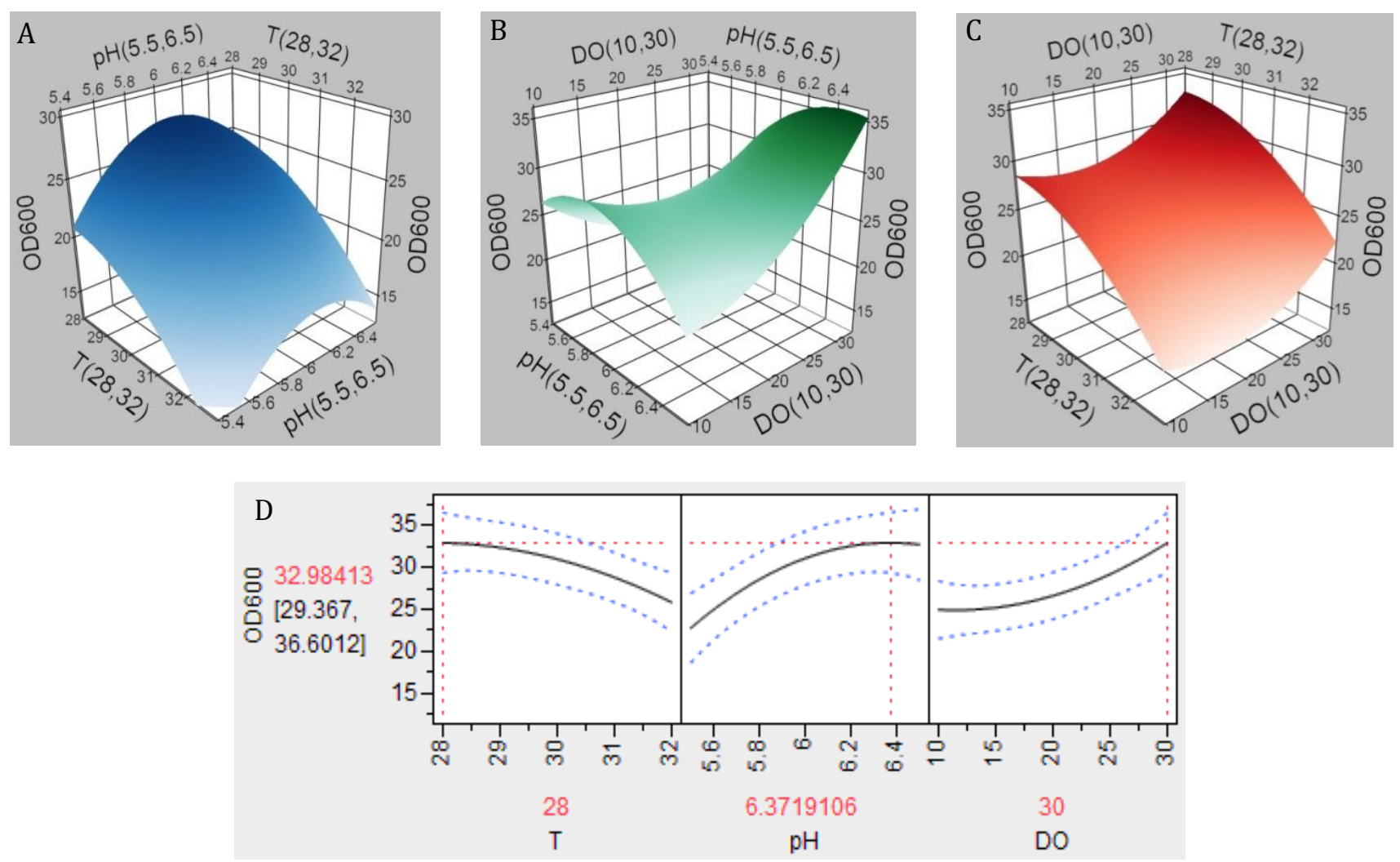

Fig. 2. Response optimization; response surface plot for A) Temperature and $\mathrm{pH}, \mathrm{B}$ ) $\mathrm{pH}$ and $\mathrm{DO}, \mathrm{C}$ ) Temperature and DO and D) Calculated optimized conditions.

Moreover, the prediction profilers shown in Fig. 3 and 4 were evaluated to obtain an initial indication of the robustness of the operating conditions. The information obtained from these plots was helpful in establishing operating ranges to confirm the confidence of the optimum parameters and predicted responses when the operating conditions have deviations. The operating conditions can deviate from optimal conditions for each parameters in order to achieve target. The slope was the criteria to choose the robust range of operating conditions. When the slope is closed to zero, it means that significant changes are not observed. Herein we consider the plateau region within $5 \%$ of $\mathrm{OD}_{600}$ loss. For example, considering 
temperature graph where the deviation of temperature was approximated -0.4 and $+1{ }^{\circ} \mathrm{C}$ from optimal conditions (the deviation of temperature was shown in Fig. 3), then the response has a small change or loss lower than $5 \%$ and the slope is closed to zero. Therefore, it could be claimed that this temperature range is robust.

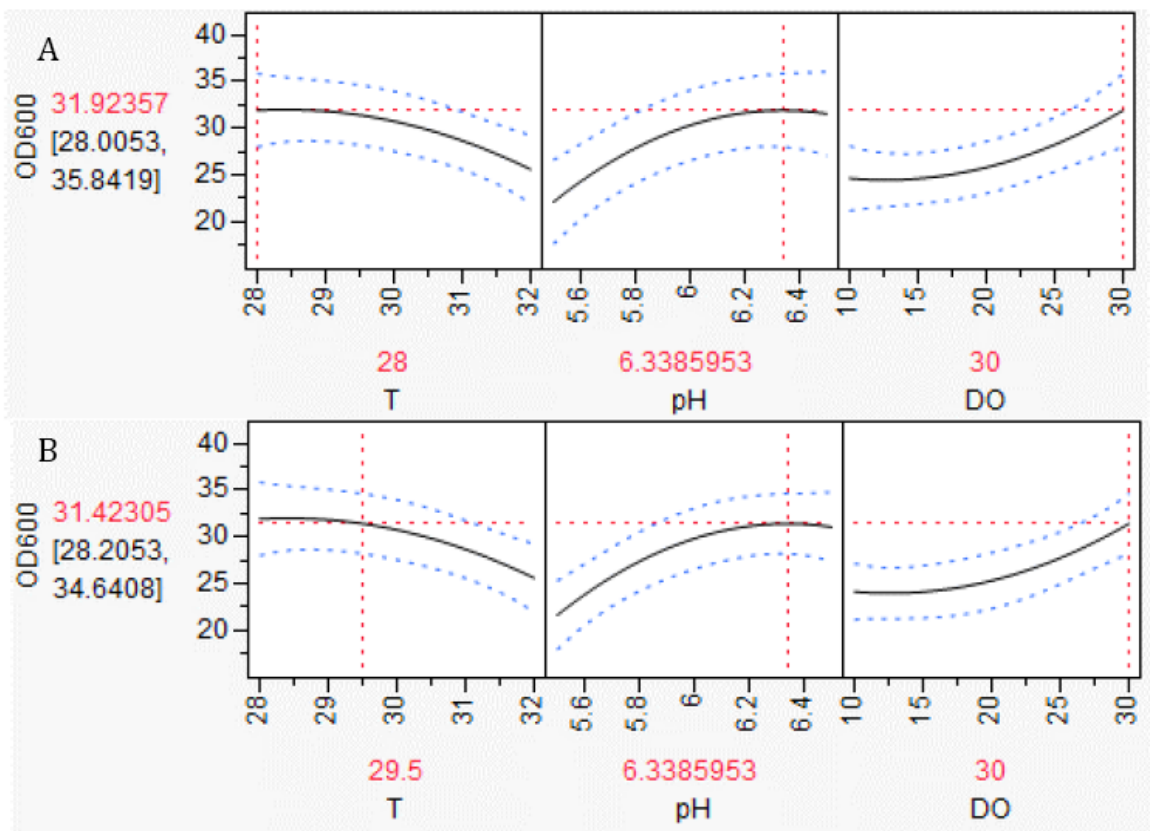

Fig. 3. Prediction profiler when temperature was changed from $28.0^{\circ} \mathrm{C}(\mathrm{A})$ to $29.5^{\circ} \mathrm{C}(\mathrm{B})$.

Fig. 4 illustrated that the robust range of temperature was $28^{\circ} \mathrm{C}$ to $29.5^{\circ} \mathrm{C}$ and pH was 6.0 to 6.5 shown by the green lines. For DO, it was no robust range observed and this was possibly due to high oxygen consumption rate of yeast. However, higher DO such as $35 \%$ or more is very difficult to control and this is one of limitation of all fermenter.

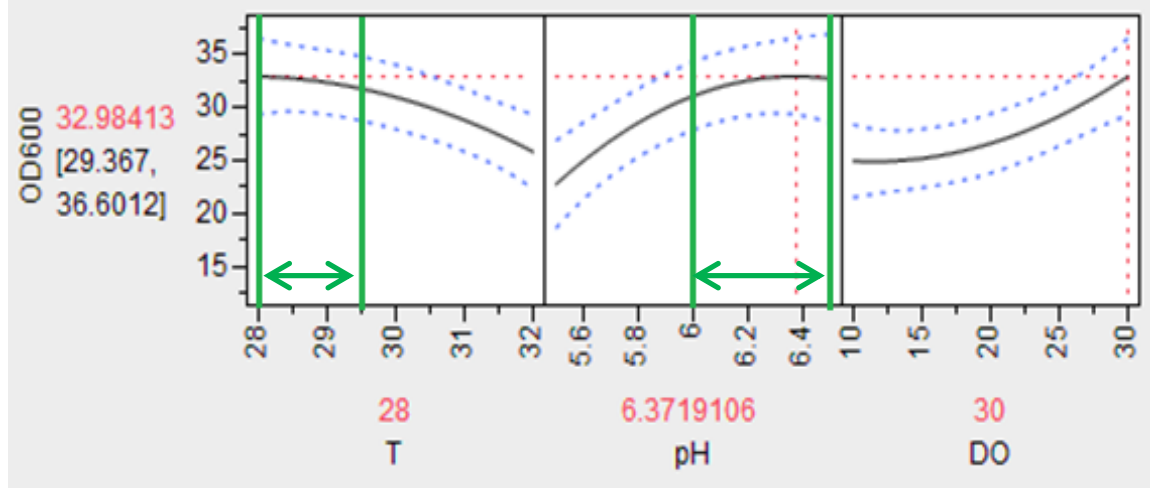

Fig. 4. Prediction profiler for ranges of operations.

\section{Conclusion}

Optimization and ranges of operations for growing Pichia pastoris KM71H were carried out in order to develop a robust process for a pilot-scale production where the process has to be well controlled and consistent. From the predicted model of growth conditions, it was found that the $\mathrm{OD}_{600}$ increases with 
decreasing temperature and increasing $\mathrm{pH}$ and D0.0ptimal conditions where temperature was $28.0^{\circ} \mathrm{C}, \mathrm{pH}$ was 6.37 and \%DO was 30 were achieved and the robust process predicted from the response surface plot ranges from $28.0^{\circ} \mathrm{C}$ to $29.5^{\circ} \mathrm{C}$ for temperature and 6.0 to 6.5 for $\mathrm{pH}$. However, validation of these ranges of operations should be further proceeded by scaling-up study.

\section{Acknowledgment}

We thank to Assist. Prof. Anan Tongta and Dr. Jorgen Borg for the cell strain. This work was supported by Coordinating Center for Thai Government Science and Technology Scholarship Students (CSTS), National Science and Technology Development Agency (NSTDA).

\section{References}

[1] Rader, R. Biopharmaceutical Product Approvals and Trends: 2012. Retrieved from the website: http://www.biopharma.com/FDA_2012_approvals_article.pdf

[2] In spite of the inclement effects of the healthcare reform bill, global pharmaceutical market is expected to mature to $\$ 220$ billion by 2016. Retrieved from the website: http://www.marketsandmarkets.com/Market-Reports/biopharmaceutical-323.html

[3] Tongta, A., et al. (2009). Development and optimization of therapeutic protein production process by recombinant Pichia pastoris: Human growth hormone production. King Mongkut's University of Technology Thonburi.

[4] (2002). Pichia Fermentation Process Guidelines. Invitrogen Co., San Diego, CA, USA.

[5] Sreekrishna, K. (2002). Pichia, optimization of protein expression. Encyclopedia of Bioprocess Technology. John Wiley \& Sons, Inc.

[6] Higgins, D. R., \& Cregg, J. M. (1998). Pichia protocols. Methods in Molecular Biolog. New Jersey, USA: Humana Press Inc.

[7] Cereghino, J. L., \& Cregg, J. M. (2000). Heterologous protein expression in the methylotrophic yeast Pichia pastoris. Fems Microbiol Rev., 24(1), 45-66.

[8] Cregg, J. M., et al. (2009). Expression in the yeast pichia pastoris. Methods Enzymol, 463, 169-89.

[9] Cregg, J. M., Vedvick, T. S., \& Raschke, W. C. (1993). Recent advances in the expression of foreign genes in pichia pastoris. Biotechnology (N Y), 11(8), 905-910.

[10] Romanos, M.A., Scorer, C. A., \& Clare, J. J. (1992). Foreign gene expression in yeast: A review. Yeast, 8(6), 423-488.

[11] Rose, M.D., Winston, F., \& Hieter, P. (1988). Methods in Yeast Genetic Laboratory Manual. Cold Spring Harbor Laboratory Press.

[12] Weinacker, D., et al. (2013). Applications of recombinant Pichia pastoris in the healthcare industry. Brazilian Journal of Microbiology, 44(4), 1043-1048.

[13] Jafari, R., Sundström, B. E., \& Holm, P. (2011). Optimization of production of the anti-keratin 8 single-chain Fv TS1-218 in pichia pastoris using design of experiments. Microb Cell Fact, 10, 34.

[14] Montgomery, D.C. (2013). Design and Analysis of Experiments. Wiley.

[15] Kincl, M., Turk, S., \& Vrečer, F. (2005). Application of experimental design methodology in development and optimization of drug release method. International Journal of Pharmaceutics, 291(1-2), 39-49.

[16] Mandenius, C. F., \& Brundin, A. (2008). Bioprocess optimization using design-of-experiments methodology. Biotechnol Prog, 24(6), 1191-203.

[17] Holmes, W. J., et al. (2009). Developing a scalable model of recombinant protein yield from Pichia pastoris: The influence of culture conditions, biomass and induction regime. Microb Cell Fact, 8, 35.

[18] Frost, J. (2013). Multiple Regression Analysis: Use Adjusted R-Squared and Predicted R-Squared to Include 
the Correct Number of Variables.

Lalintip Hocharoen was born in Chiang Mai, Thailand on Aug 12 ${ }^{\text {th }}$ 1982. She received her B.Sc (chemistry) from Chiang Mai University in 2006 and her Ph.D (biochemistry) from the Ohio State University, Ohio, USA in 2012. In her Ph.D studies, she had experienced with protein expression using microbial fermentation technology and assays related to kinetics, protein characterizations, and drug designs. She is currently a process development specialist at National Biopharmaceutical Facility (NBF), KMUTT, Bangkok, Thailand where she has been involved in technology transfers for microbial platform technologies including DNA vaccines and therapeutic protein production as well as process development for Good Manufacturing Practice (GMP) master cell bank productions.

Kosin Jittipanyakul was born on March 17, 1991. He has joined a master degree program on biopharmaceutical engineering at Chemical Engineering Department, KMUTT, Bangkok, Thailand since 2014. 